\title{
Nutritional Knowledge, Parenting Styles and Feeding Practices of a South African Sample of Parents
}

\section{Melissa Brown \& Nicolette V. Roman}

To cite this article: Melissa Brown \& Nicolette V. Roman (2019) Nutritional Knowledge, Parenting Styles and Feeding Practices of a South African Sample of Parents, Ecology of Food and Nutrition, 58:6, 529-547, DOI: 10.1080/03670244.2019.1641800

To link to this article: https://doi.org/10.1080/03670244.2019.1641800

曲 Published online: 18 Jul 2019.

Submit your article to this journal $\pi$

Џll Article views: 232

Q View related articles $\asymp$

View Crossmark data $־$ 


\title{
Nutritional Knowledge, Parenting Styles and Feeding Practices of a South African Sample of Parents
}

\author{
Melissa Brown (D) and Nicolette V. Roman \\ Child and Family Studies, Social Work Department, University of the Western Cape, Bellville, South \\ Africa
}

\begin{abstract}
Parenting can be considered as being an all-encompassing network of development for children. Children learn about eating not only through their own experiences but also by watching others. Mothers and children show similar patterns of food acceptance and food preferences. Children's intake of fruit and vegetables was positively related to parents' intake of fruit and vegetables. The current study used self-reported data from parents/primary caregivers' children aged 3-18 covering sociodemographic characteristics, feeding style dimensions ('control overeating', 'emotional feeding', 'encouragement to eat' and 'instrumental feeding') and parenting style dimensions ('involvement' and 'strictness'). The results suggest, that in general, parents were inclined to encourage balance and variety in the food intake of their children, modeling healthy eating behavior, as well as monitoring the food intake of children while restricting unhealthy foods. Further research is needed into whether parents' diets affect children's food choices feeding.
\end{abstract}

\section{KEYWORDS}

Parenting; nutritional knowledge; parent psychological control; feeding practices

\section{Parenting}

Parenting refers to child-rearing activities which aims to promote and support children's development (Jansen et al. 2014). One common approach has been to conceptualize parenting according to relatively enduring 'styles' of interaction (i.e., authoritative, authoritarian, permissive and neglectful). These styles of interaction are underpinned by two key behavioural dimensions - the extent to which parents are responsive to their children's needs and demands (parental 'responsiveness'), and the extent to which parents set clear limits around their children's behavior and consistently ensure compliance (parental 'demandingness' or 'control') (Jansen et al. 2014). Parenting can be considered as being an all-encompassing network of development for children (Davids, Roman, and Leach 2015). Parents affect the behavior, health, and well-being of their children (Roman 2015) and is an important predictor of children's social and emotional adjustment (Kiff, Lengua, and Zalewski 2011). It is a key element in the socialization and rearing of children, as parental nurturing contributes towards 
learning and early development. These aspects influence children's adjustment across the lifespan (Baumrind, 1967; Louw and Louw, 2007). The practice of parental warmth and support in the parent-child relationship includes the display of responsiveness, positive affect, and support (Carlo et al. 2010). This type of parenting often sees children and adolescents who have developed healthy attachment relationships as well as displaying pro-social behaviors (Carlo et al. 2010). Conversely, harsh, unresponsive, and neglectful parenting generally results in more negative outcomes (e.g., poorer social functioning) (Moran, Turiano, and Gentzler 2018).

\section{Parenting styles}

Parenting style can be defined as a constellation of attitudes and beliefs towards the child that create an emotional climate in which parents' behaviors are expressed (Wang et al. 2017).

These behaviors are expressed through four types of parenting styles, varying along two dimensions (demandingness and responsiveness): (1) authoritative parenting, associated with a high level of demandingness and rules with high responsiveness to the child; (2) authoritarian parenting, linked to high demandingness but low responsiveness characterized by rules but with less influence from the child's needs; (3) indulgent parenting, combining low demandingness and high responsiveness with few rules but high engagement with the child's needs; and (4) uninvolved parenting, which is associated with both low demandingness and low responsiveness. An authoritative parenting style is generally associated with the most positive child outcomes, such as higher school performance (Shloim et al. 2015) and with a more positive home food environment (Johnson et al. 2012). The approach which parents use is an important determinant for how the child feels and behaves. For example, the use of parental warmth and support results in children's psychological adjustment. Parental warmth (associated with authoritative parenting) may, therefore, be more influential than parental control (the use of limit setting and support for children's autonomy) in the promotion of children's emotional and psychological adjustment (Schuman et al. 2007). Psychological control is the extent to which parents try to control the child's emotional state or beliefs. Parents may use guilt induction or make the child feel they will not be loved if they do not do what their parents want. Psychological control includes strategies and behaviors such as autonomy granting, over-control, and intrusive and overly attentive parenting (Kiff, Lengua, and Zalewski 2011). The core of psychological control is that it assaults the child's self. Behavior control refers to the extent to which parents ask kids to constrain their behavior to meet the needs of others. The application of behavior control may be viewed as a parent being strict; however, it is better conceptualized as the parents' expectation that the child conforms to high standards. It also captures the extent to which parents follow through on rules they set (Davids, Roman, and Leach 2015; Schuman et al. 2007). Parental behavior 
control demonstrates behaviors and actions related to discipline, limit setting, and monitoring (Kiff, Lengua, and Zalewski 2011). Parents who practice styles that are generally warm and supportive are considered important contributors to prosocial and positive developmental outcomes, while parents who are too controlling will often create developmental outcomes which undermine positive outcomes (Carlo et al. 2010). Children's eating patterns and preferences are an outcome of the interaction of innate and learned factors embedded in the context of parentchild interactions (Lipowska et al. 2018).

\section{Parenting, child weight status, feeding styles, and practice}

Previous research has suggested a relationship between particular parental feeding strategies and children's energy intake, diet quality and body weight (van der Horst and Sleddens 2017). As a result, parents and their parenting styles play an important role in shaping children's eating behaviors through the approaches and feeding styles they use (Wang et al. 2017). Feeding styles may be viewed as a sub-category of parenting styles that are specific to mealtimes and therefore the same dimensions of demandingness and responsiveness are applied in the feeding context (Blissett 2011; Hughes et al. 2005; Ventura and Birch 2008). Thus, with an authoritative feeding style, parents actively encourage their child to eat but achieve this through supportive behaviors, including rules explained in a sensitive way. With an authoritarian feeding style, parents encourage eating through parent-centric rules, e.g., parents permit their child freedom to each when they wish, parents negotiate with children to eat well praising them, few meal routines or requires children to eat certain foods and avoid others, while punishing food-related transgressions. (Shloim et al. 2015). Feeding practices are specific techniques or behaviors usually used to facilitate or limit ingestion of foods. They include practices such as pressure to eat, restriction, monitoring of the child's food intake, or the use of rewards for food consumption. The two most commonly studied feeding practices are restriction and pressure to eat (Fisher and Birch, 1999; Galloway et al. 2006). Scaglioni et al. (2011) believe that the strategies parents use, such as over-control, restriction, pressure to eat and promise of rewards, all have negative effects on children's food acceptance. Parental feeding practices, particularly restriction of palatable foods and pressure to eat, have been related to children's body weight and energy intakes (Galloway et al. 2005, 2006)

Shloim et al. (2015) found associations between parenting styles and the BMI of children. Uninvolved, indulgent and highly protective parenting was associated with higher child BMI, whereas authoritative parenting was associated with a healthy BMI. Similarly, indulgent feeding was consistently associated with risk of obesity within cross-sectional studies. Specific feeding practices such as restriction and pressure to eat were linked to BMI, 
especially within cross-sectional studies (Shloim et al. 2015). Shloim et al. (2015) found that here child traits were measured, the feeding practice appeared to be responsive to the child. Therefore, restriction was applied to children with a high BMI and pressure to eat applied to children with a lower BMI. However, studies from Australia and the United Kingdom have found no association between parental restriction and child weight (Webber et al. 2010; Campbell et al. 2010; Carnell and Wardle, 2007) and longitudinal studies have shown no association between pressure to eat and child adiposity measures (Spruijt-Metz et al. 2006; Webber et al. 2010). Although it has been theorized that parental beliefs and practices may be modifiable determinants to prevent pediatric obesity and excessive adiposity (Savage, Fisher, and Birch 2007), it is evident that the relationships between parental feeding practices and risk for obesity in children are complex, and do not appear to carry the same effect among all individuals. The public selects their foods from hundreds or even thousands of products, many of which are designed and marketed to maximize their appeal (Brown and Roman 2015). Parents are important agents through which food preferences and intake patterns are set, via both direct and indirect influences, from controlling the child's intake to passively modeling a healthy or unhealthy diet (Shloim et al. 2015). Parental pressure to eat has been associated with decreased preference and consumption of the pressured food, lower fruit and vegetable intake, picky eating, and lower weight in children (Galloway et al. 2005, 2006). Pressure to eat has been reported to cause chaos and stress during mealtimes and to negatively impact children's associations with food (Cardel et al. 2012).

Parental feeding practices could influence the child's eating patterns, which leads to the development of impaired nutritional knowledge as well as nutritional choices which impact children later in life through an increase of noncommunicable diseases (NCD) such as cardiovascular disease. A key modifiable risk factor for NCDs is overweight and obesity (Webber et al. 2012). Obesity in children aged 3-15 years relates to familial and environmental factors, including incorrect eating habits. It is projected that this trend will reach $9.1 \%$ or 60 million children in 2020. The estimated prevalence of overweight and obese children in Africa in 2010 was 8.5\% and is expected to reach 12.7\% in 2020 (De Onis, Blössner, and Borghi 2010). Obesity is a complex condition with serious social and psychological dimensions, that affects virtually all age and socioeconomic groups and threatens to overwhelm both developed and developing countries (WHO, 2008). Obesity is related to many health-related conditions in children such as diabetes, joint disorders, difficulty breathing and heart disease (Paulis 2016). The interaction between parents and children at the family meal is bi-directional and informed by several different environmental factors (e.g., income and culture), parental attributes (beliefs, attitudes, behaviors), and child characteristics (temperament, eating traits and learned behaviors). 


\section{The current study}

To select a healthy diet for their children, parents must be able to ignore the advertiser's blandishments and the immediate appeal to the palate and draw on a complete technical and scientific knowledge - based on nutrients, food, and health (Paramenter, Waller, and Wardle 2000). At a minimum, parents need to know the prevailing nutritional recommendations, be able to apply those to the food products they are considering and combine recommendations to make the best food choices for their children (Brown and Roman 2014). This is particularly relevant to South Africa, which is undergoing socio-economic transformation, with increasing urbanization, coupled with attendant lifestyle habits to promote sedentariness and patronage of fast - food restaurants (Toriola et al. 2012). Previous studies have suggested a relationship between particular parental feeding strategies and children's energy intake, diet quality and body weight (van der Horst and Sleddens 2017). Parental demographic characteristics, including socioeconomic status and parental weight, have also been linked to children's dietary intake and body mass index (BMI). Thus, the purpose of this study was to examine the prevalence of nutritional knowledge, parenting styles and feeding practices of parents and primary caregivers with children aged 3-18 years old.

\section{Methodology}

\section{Participants}

The study followed a quantitative approach with a cross-sectional design. A sample of 102 South African parents and caregivers with a Mean Age of $38.48(S D=8.65)$ years agreed to be part of the study. Of the participants $11.26 \%$ $(\mathrm{N}=15)$ were male and $88.74 \%(\mathrm{~N}=87)$ female. Of these parents and caregivers $52 \%(\mathrm{~N}=53)$ were Coloured, $13 \%(\mathrm{~N}=13)$ Black African, $22 \%(\mathrm{~N}=22)$ White, $13 \%(\mathrm{~N}=13)$ Indian/Asian and $1 \%(\mathrm{~N}=1)$ were Other.

\section{Data collection procedure}

Parents and caregivers of children ages 3-18 years old were recruited via an online social media platform. A search on Facebook for groups relating to parents and primacy caregivers was conducted. Criteria for selection included meal preparation, exercise, general health, and wellness of families. A list of four online groups on Facebook, specifically within South Africa, was identified. All four online groups consisted of members who met the criteria of parents and caregivers. The identified groups had their own Facebook group rules. They were closed groups, with each having their own administrator who was responsible for curating posts. In order to be accepted into the groups, a potential member had to answer three questions and adhere to group policy. Group policies included respect for one 
another, not selling or advertising a service, and not offering a service to the members of the group. Some groups indicated that should the policy not be adhered to the offending member would be removed from the group. The Facebook group administration of each group was approached via email and the study abstract proposal was sent to them, along with further details asking if they were open to sharing a post or forum message on their wall to highlight the study and recruit study participants.

The research was given permission to join the closed groups by all four group administrators. On a selected day, a message was posted on the groups Facebook wall explaining the study purpose, design as well as if the members had children under the age of 18 . The message requested if members would be free to participant in the current study. On the day of message posting, there were a total of 5020 followers across the four groups. In each group, it was not possible to see who were active group members; therefore, the researcher was unable to determine who was actively engaging with the groups' daily or weekly content. The Facebook post included a google link to the online questionnaire where a consent form was included as the first page of the questionnaire, participants needed to click accept as a means of consent and that they agreed to being either parents or primary caregivers of children between 3 and 18 years old. If they did not agree they were thanked for taking the time to participate in the study and their survey link closed. A total of four reminder posts were generated in order to remind users of the questionnaire stating clearly that it was for research purposes and not for any incentive. One hundred and two members of the four groups completed the questionnaire and were included in the study.

\section{Measuring instrument}

Online Google questionnaire was created to collect the data which generated a link that was used in the Facebook post. The questionnaire contained a basic demographic section (age, gender, race), questions on current employment status, questions on household makeup (i.e., head of the household and family structure, including if there is a father in the home), as well as questions regarding participants education level as well as five specific sections as outlined (Parents as Social Context Questionnaire, Emotion-Related Parenting Styles, Comprehensive Child Feeding Practice Questionnaire, and the General Nutritional Knowledge Questionnaire). The Parents as Social Context Questionnaire (PASCQ) (Skinner, Regan, and Wellborn, 1986) was used. Additionally, the Emotion-Related Parenting Styles (ERPS) scale (Paterson et al. 2012) questionnaire was attached. The ERPS is a 20-item scale, based on meta-emotion theory (Gottman et al. 1997), which contained four subscales. Each subscale measures a different emotionrelated parenting style - that is, PA (parental acceptance of negative emotions [emotion approving]), PR (parental rejection of negative emotions [emotion disapproving]), EC (emotion coaching of negative emotions [active socialization]), 
and UI (uncertain/ineffective socialization of negative emotions [passive socialization]). Each subscale has five gender-neutral items. Examples include the following: PA ("I want my child to experience sadness"), PR ("Children act sad to get their way"), EC ("When my child is angry, it's time to problem solve"), and UI ("When my child is sad, I'm not quite sure what he or she wants me to do"). Responses were rated along a 4-point Likert-type scale from 1 (Not at all true) to 4 (Very true). Total subscale scores were calculated by summing the items of each subscale. High scores represented endorsement of the associated parenting style.

The Comprehensive Child Feeding Practice Questionnaire (CFPQ; MusherE-Eisenman and Holub, 2007) and the General Nutritional Knowledge Questionnaire (GNKQ; Parmenter and Wardle, 2000) for adults were also included to gain a perspective on nutritional knowledge of parents. The CFPQ contained 12 items which indicate different feeding practices of primary caregivers: (1) child control (five items); (2) emotion regulation (three items); (3) encourage balance and variety (four items); (4) environment (four items); (5) food as reward (three items); (6) involvement (three items); (7) modelling (four items); (8) monitoring (four items); (9) pressure (four items); (10) restriction for health (four items); (11) restriction for weight control (eight items); and (12) teaching about nutrition (three items). Participants had to respond on a 5-point Likert scale ranging from $1=$ Never to $5=$ Always.

The General Nutritional Knowledge Questionnaire (GNKQ) covered current dietary recommendations, sources of nutrients, everyday food choices, and diet-disease relationships. This helped highlight the behavior of participants with regard to their food choices as it underlined the main aspects relating to knowledge about dietary behavior. These aspects are as follows: Do people know what the current expert dietary recommendations are? Do they know which foods provide the nutrients referred to in the recommendations? Can they choose between different foods to identify the healthiest ones? Do they know what the health implications of eating or failing to eat particular foods are? Responses to the GNKQ questions would be able to generate a representation of a comprehensive assessment of nutritional knowledge. Participants had to respond on a 3- or 4-point Likert scale ranging from $1=$ No to $3=$ Yes, $1=$ Same to $4=$ Not sure, or ticking the box which they found appropriate. Additionally, the Parental Psychological Control (Barber 2002) questionnaire was used to measure parental psychological control of both mothers and fathers. Barber's eightitem scale, a revised version of the Children's Report of Parental Behaviour Inventory (CRPBI; Schaefer, 1965), was used in this study. Participants were asked to describe their mothers and fathers by choosing responses on a 3-point Likert scale with "not like her" = 1; "somewhat like her" = 2 and "a lot like her" $=3$. The higher the scores the more controlling mothers and fathers are. 


\section{Data analysis}

The questionnaires were electronically scored according to the requirements of the instruments. Data were analyzed using SPSS version 22. The data were analyzed using descriptive statistics (frequencies and mean scores) for the sub-scales of parenting styles, child feeding practices, nutritional knowledge, and psychological control.

\section{Ethical considerations}

The research project was registered with the University of the Western Cape for ethical clearance as the current study was a part of a $\mathrm{PhD}$ study. Participants of the study were informed that the study was voluntary and by clicking on the link a pop-up message appeared on screen that stated that partaking in the study was anonymous and confidential as well as them being able to leave at any time.

\section{Results}

Demographic characteristics of participants are presented in Table 1.

Of the 102 participants who completed the questionnaire, $87(85.2 \%)$ of participants were female and $15(14.8 \%)$ were males. Forty-two $(39.9 \%)$ of respondents indicated that they are the head of the home, while $60(56.1 \%)$ indicated their Spouse/Partner is 4 (3.7\%) indicated their father is the head of the home, with $1(0.9 \%)$ indicating that extended family (aunt/cousin/uncle) is the head. One hundred (98.0\%) of the participants had post-matric education, with $60(55.8 \%)$ of them having a degree. All participants had children between the ages of 3-18 years. Parents were alerted in the study when accepting to participant that they should think of a maximum of two children they had who feel into the age breakdown when reviewing the questionnaire. This is also addressed in the limitations of the study.

In Table 2, the results suggest that the most prevalent parenting approach was autonomy and supportive parenting $(\mathrm{M}=3.72, S D=.33)$ followed by parental warmth $(\mathrm{M}=3.70, S D=0.37)$. Chaotic parenting was the least prevalent $(M=1.83, S D=0.52)$.

Table 1. Demographic characteristics.

\begin{tabular}{lrrrrr}
\hline \multicolumn{7}{c}{ Descriptive Statistics } \\
\hline Age & N & Minimum & Maximum & \multicolumn{1}{c}{$M$} & $S D$ \\
Household income per month & 102 & 26 & 72 & 38.48 & 8.65 \\
Number of children in the home & 93 & 577 & 150000 & 43232.01 & 28703.92 \\
Height in cm & 102 & 0 & 5 & 1.91 & .95 \\
Weight in kg & 101 & 105 & 190 & 163.30 & 10.36 \\
\hline
\end{tabular}


Table 2. Descriptive for parenting.

\begin{tabular}{lccccc}
\hline \multicolumn{7}{c}{ Parenting Styles and Practices * } \\
\hline Variables & $\mathrm{N}$ & Minimum & Maximum & M & SD \\
\hline Parental Warmth & 81 & 2.40 & 4.00 & 3.70 & .37 \\
Parental rejection & 80 & 1.00 & 3.40 & 1.85 & .61 \\
Structure in parenting & 79 & 2.50 & 4.00 & 3.55 & .37 \\
Chaotic parenting & 80 & 1.00 & 4.00 & 1.83 & .52 \\
Autonomy and supportive parenting & 79 & 2.80 & 4.00 & 3.72 & .33 \\
Cohesive parenting & 81 & 1.00 & 3.80 & 2.10 & .62 \\
Parental acceptance & 81 & 1.20 & 4.00 & 2.81 & .65 \\
Parental rejection parenting & 79 & 1.00 & 4.00 & 2.14 & .65 \\
Emotional coaching parenting & 81 & 1.00 & 4.00 & 3.60 & .54 \\
Uncertain and ineffective & 76 & 1.00 & 3.50 & 1.94 & .65 \\
Psychological control parenting & 99 & 1.00 & 2.00 & 1.22 & .22 \\
\hline
\end{tabular}

In Table 3, Encouragement scored the highest in child feeding practices $(\mathrm{M}=4.07, \mathrm{SD}=0.71)$, followed by Modelling $(\mathrm{M}=3.66, \mathrm{SD}=.86)$ while Emotional regulation scored the lowest $(\mathrm{M}=1.74, \mathrm{SD}=.65)$.

Table 4 presents the results of a regression analysis which assesses the effects of parenting practices on feeding style. The final model includes all the predictors accounting for $11 \%(\Delta \mathrm{R} 2=0.11)$ of the variance in teaching in feeding style. The results suggest that only parental acceptance in emotion-focused parenting ( $\beta=0.36,<p=.05)$ significantly predicted teaching in feeding style.

Table 5 presents the results of a regression analysis which assesses the effects of parenting practices on feeding style. The final model includes all the predictors accounting for $21 \%(\Delta \mathrm{R} 2=0.21)$ of the variance in restrictions for weight feeding style. The results suggest that only psychologically controlling parenting ( $\beta=0.49,<p=.05$ ) significantly predicted weight in feeding style.

Table 6 presents the results of a regression analysis which assesses the effects of parenting practices on feeding style. The final model includes all the predictors accounting for $14 \%\left(\Delta \mathrm{R}^{2}=0.14\right)$ of the variance in restrictions for height feeding style. The results suggest that only psychologically controlling parenting $(\beta=0.36$, $<p=.05)$ significantly predicted restrictions for height feeding style.

Table 3. Comprehensive child feeding practice.

\begin{tabular}{lccccc}
\hline \multicolumn{5}{c}{ Comprehensive child feed practice** } \\
\hline Variables & $\mathrm{N}$ & Minimum & Maximum & $M$ & $S D$ \\
\hline Child Control & 102 & 1.00 & 4.00 & 2.46 & .56 \\
Emotional regulation & 102 & 1.00 & 3.33 & 1.74 & .65 \\
Encouragement & 101 & 2.25 & 5.00 & 4.07 & .71 \\
Environment & 100 & 1.50 & 4.00 & 3.10 & .39 \\
Rewarding & 100 & 1.00 & 5.00 & 2.29 & .90 \\
Involvement & 102 & 1.00 & 5.00 & 2.86 & .90 \\
Modelling & 96 & 1.25 & 5.00 & 3.66 & .86 \\
Monitoring & 99 & 1.50 & 5.00 & 3.74 & .93 \\
Pressure & 98 & 1.00 & 4.50 & 2.74 & .66 \\
Restrict by height & 96 & 1.00 & 5.00 & 3.23 & .898 \\
Restrict by weight & 98 & 1.00 & 4.00 & 1.81 & .81 \\
Teach & 101 & 5.00 & 3.00 & .79 \\
\hline
\end{tabular}


Table 4. Predicting teaching in feeding style.

\begin{tabular}{|c|c|c|c|c|c|c|}
\hline \multicolumn{7}{|c|}{ Predicting Teaching in Feeding Style } \\
\hline Variables & $F$ & B & $S E$ & $\beta$ & $t$ & $p$ \\
\hline Constant & 1.661 & 3.25 & & & & \\
\hline Psychologically controlling parenting & & 0.06 & 0.40 & 0.03 & 0.16 & 0.87 \\
\hline Parental warmth & & 0.11 & 0.18 & 0.11 & 0.62 & 0.54 \\
\hline Parental rejection & & 0.18 & 0.20 & 0.16 & 0.92 & 0.36 \\
\hline Structure in parenting & & 0.01 & 0.18 & 0.01 & 0.06 & 0.95 \\
\hline Chaotic parenting & & 0.02 & 0.27 & 0.01 & 0.07 & 0.95 \\
\hline Autonomy supportive parenting & & -0.21 & 0.18 & -0.22 & -1.18 & 0.25 \\
\hline Cohesive parenting & & -0.13 & 0.22 & -0.10 & -0.57 & 0.58 \\
\hline Parental acceptance & & 0.40 & 0.16 & 0.36 & 2.49 & $0.02^{*}$ \\
\hline Parental emotional rejection parenting & & -0.36 & 0.21 & -0.32 & -1.73 & 0.09 \\
\hline Emotion coaching & & -0.20 & 0.15 & -0.25 & -1.33 & 0.19 \\
\hline Uncertain and ineffective parenting & & -0.01 & 0.18 & -0.01 & -0.06 & 0.95 \\
\hline
\end{tabular}

$\Delta R^{2}=0.11 . p<.05$

Table 5. Predicting restrictions for weight feeding style.

\begin{tabular}{lrrrrrr}
\hline \multicolumn{7}{c}{ Predicting Restriction for Weight Feeding Style } \\
\hline Variables & \multicolumn{1}{c}{ F } & \multicolumn{1}{c}{ SE } & $\beta$ & \multicolumn{1}{c}{$t$} & \multicolumn{1}{c}{} \\
\hline Constant & 2.313 & -0.33 & & & & \\
Psychologically controlling parenting & & 1.56 & 0.51 & 0.49 & 3.05 & $0.00^{*}$ \\
Parental warmth & & 0.09 & 0.22 & 0.07 & 0.40 & 0.70 \\
Parental rejection & & 0.24 & 0.24 & 0.16 & 0.10 & 0.33 \\
Structure in parenting & & 0.16 & 0.22 & 0.12 & 0.72 & 0.47 \\
Chaotic parenting & -0.52 & 0.34 & -0.30 & -1.52 & 0.14 \\
Autonomy supportive parenting & & -0.04 & 0.22 & -0.03 & -0.20 & 0.84 \\
Cohesive parenting & 0.15 & 0.28 & 0.09 & 0.54 & 0.59 \\
Parental acceptance & 0.26 & 0.20 & 0.18 & 1.32 & 0.19 \\
Parental emotional rejection parenting & & -0.12 & 0.26 & -0.08 & -0.47 & 0.64 \\
Emotion coaching & & -0.18 & 0.19 & -0.17 & -0.95 & 0.35 \\
Uncertain and ineffective parenting & & 0.15 & 0.22 & 0.11 & 0.67 & 0.51 \\
\hline
\end{tabular}

$\Delta \mathrm{R} 2=0.21 . p<.05$

Table 6. Predicting restrictions for height feeding style.

\begin{tabular}{|c|c|c|c|c|c|c|}
\hline \multicolumn{7}{|c|}{ Predicting Restriction for Height Feeding Style } \\
\hline Variables & $F$ & B & SE & $\beta$ & $t$ & $p$ \\
\hline Constant & 1.829 & 1.87 & & & & \\
\hline Psychologically controlling parenting & & 1.22 & 0.58 & 0.36 & 2.09 & $0.04^{*}$ \\
\hline Parental warmth & & -0.29 & 0.27 & -0.20 & -1.07 & 0.29 \\
\hline Parental rejection & & 0.26 & 0.28 & 0.16 & 0.93 & 0.36 \\
\hline Structure in parenting & & -0.37 & 0.25 & -0.26 & -1.47 & 0.15 \\
\hline Chaotic parenting & & -0.26 & 0.39 & -0.14 & -0.67 & 0.51 \\
\hline Autonomy supportive parenting & & 0.36 & 0.27 & 0.25 & 1.36 & 0.18 \\
\hline Cohesive parenting & & 0.23 & 0.31 & 0.13 & 0.73 & 0.47 \\
\hline Parental acceptance & & 0.23 & 0.23 & 0.15 & 1.03 & 0.31 \\
\hline Parental emotional rejection parenting & & -0.36 & 0.29 & -0.22 & -1.22 & 0.23 \\
\hline Emotion coaching & & -0.06 & 0.22 & -0.05 & -0.27 & 0.79 \\
\hline Uncertain and ineffective parenting & & 0.14 & 0.25 & 0.10 & 0.58 & 0.57 \\
\hline
\end{tabular}

$\Delta R^{2}=0.14 . p<.05$ 
Table 7 presents the results of a regression analysis which assesses the effects of parenting practices on feeding style. The final model includes all the predictors accounting for $28 \%\left(\Delta \mathrm{R}^{2}=0.28\right)$ of the variance in monitoring feeding style. The results suggest that psychologically controlling parenting $(\beta=-0.34,<p=.05)$ and cohesive parenting $(\beta=-0.42,<p=.05)$ significantly negatively predicted monitoring feeding style. Parental rejection $(\beta=0.24,<p=.05)$ significantly positively predicted monitoring feeding style.

Table 8 presents the results of a regression analysis which assesses the effects of parenting practices on feeding style. The final model includes all the predictors accounting for $6 \%\left(\Delta \mathrm{R}^{2}=0.06\right)$ of the variance in modeling feeding style. The results suggest that parental warmth $(\beta=-0.36,<p=.05)$ significantly positively predicted modeling feeding style.

Table 9 presents the results of a regression analysis which assesses the effects of parenting practices on feeding style. The final model includes all the predictors accounting for $26 \%\left(\Delta \mathrm{R}^{2}=0.26\right)$ of the variance in involvement

Table 7. Predicting monitoring feeding style.

\begin{tabular}{|c|c|c|c|c|c|c|}
\hline \multicolumn{7}{|c|}{ Predicting Monitoring Feeding Style } \\
\hline Variables & $F$ & $B$ & $S E$ & $\beta$ & $t$ & $p$ \\
\hline Constant & 2.991 & 6.00 & & & & \\
\hline Psychologically controlling parenting & & -1.13 & 0.49 & -0.34 & -2.33 & $0.03^{*}$ \\
\hline Parental warmth & & -0.20 & 0.24 & -0.14 & -0.83 & 0.41 \\
\hline Parental rejection & & 0.48 & 0.24 & 0.31 & 2.00 & $0.05^{*}$ \\
\hline Structure in parenting & & -0.11 & 0.22 & -0.08 & -0.51 & 0.61 \\
\hline Chaotic parenting & & 0.44 & 0.33 & 0.25 & 1.36 & 0.18 \\
\hline Autonomy supportive parenting & & -0.10 & 0.22 & -0.08 & -0.44 & 0.66 \\
\hline Cohesive parenting & & -0.72 & 0.27 & -0.42 & -2.68 & $0.01 *$ \\
\hline Parental acceptance & & 0.16 & 0.20 & 0.11 & 0.83 & 0.41 \\
\hline Parental emotional rejection parenting & & -0.34 & 0.26 & -0.22 & -1.32 & 0.19 \\
\hline Emotion coaching & & 0.04 & 0.18 & 0.04 & 0.22 & 0.83 \\
\hline Uncertain and ineffective parenting & & -0.13 & 0.21 & -0.09 & -0.61 & 0.55 \\
\hline
\end{tabular}

$\Delta R^{2}=0.28 . p<.05$

Table 8. Predicting modeling feeding style.

\begin{tabular}{|c|c|c|c|c|c|c|}
\hline \multicolumn{7}{|c|}{ Predicting Modelling Feeding Style } \\
\hline Variables & $F$ & $B$ & $S E$ & $\beta$ & $t$ & $p$ \\
\hline Constant & 1.341 & 4.88 & & & & \\
\hline Psychologically controlling parenting & & -0.00 & 0.56 & 0.00 & -0.00 & 0.10 \\
\hline Parental warmth & & 0.52 & 0.26 & 0.36 & 2.02 & $0.05^{*}$ \\
\hline Parental rejection & & 0.17 & 0.28 & 0.12 & 0.60 & 0.55 \\
\hline Structure in parenting & & -0.01 & 0.25 & -0.01 & -0.06 & 0.96 \\
\hline Chaotic parenting & & -0.24 & 0.38 & -0.13 & -0.63 & 0.53 \\
\hline Autonomy supportive parenting & & -0.39 & 0.25 & -0.29 & -1.52 & 0.14 \\
\hline Cohesive parenting & & -0.52 & 0.31 & -0.29 & -1.65 & 0.11 \\
\hline Parental acceptance & & -0.10 & 0.23 & -0.07 & -0.44 & 0.66 \\
\hline Parental emotional rejection parenting & & -0.31 & 0.30 & -0.20 & -1.05 & 0.30 \\
\hline Emotion coaching & & 0.13 & 0.21 & 0.12 & 0.63 & 0.53 \\
\hline Uncertain and ineffective parenting & & 0.16 & 0.25 & 0.11 & 0.64 & 0.53 \\
\hline
\end{tabular}

$\Delta R^{2}=0.06, p<.05$ 
Table 9. Predicting involvement feeding style.

\begin{tabular}{|c|c|c|c|c|c|c|}
\hline \multicolumn{7}{|c|}{ Predicting Involvement Feeding Style } \\
\hline Variables & $F$ & $B$ & SE & $\beta$ & $t$ & $p$ \\
\hline Constant & 2.959 & 4.19 & & & & \\
\hline Psychologically controlling parenting & & -0.11 & 0.55 & -0.03 & -0.20 & 0.85 \\
\hline Parental warmth & & -0.53 & 0.24 & -0.32 & -2.16 & $0.04^{*}$ \\
\hline Parental rejection & & 0.60 & 0.27 & 0.34 & 2.27 & $0.03^{*}$ \\
\hline Structure in parenting & & -0.17 & 0.24 & -0.11 & -0.69 & 0.49 \\
\hline Chaotic parenting & & 0.75 & 0.37 & 0.37 & 2.04 & $0.05^{*}$ \\
\hline Autonomy supportive parenting & & -0.38 & 0.24 & -0.26 & -1.57 & 0.12 \\
\hline Cohesive parenting & & -0.51 & 0.29 & -0.27 & -1.75 & 0.09 \\
\hline Parental acceptance & & -0.01 & 0.21 & -0.01 & -0.04 & 0.97 \\
\hline Parental emotional rejection parenting & & -0.23 & 0.29 & -0.14 & -0.81 & 0.42 \\
\hline Emotion coaching & & -0.21 & 0.21 & -0.17 & -1.03 & 0.31 \\
\hline Uncertain and ineffective parenting & & 0.02 & 0.24 & 0.01 & 0.07 & 0.95 \\
\hline
\end{tabular}

feeding style. The results suggest that parental warmth $(\beta=-0.32,<p=.05)$ significantly negatively predicted monitoring feeding style. Parental rejection $(\beta=0.34,<p=.05)$ and chaotic parenting $(\beta=0.37,<p=.05)$ significantly positively predicted involvement feeding style.

\section{Knowledge of parents: dietary recommendations}

Participants were asked to indicate the extent to which they thought health experts recommended eating certain foods. Some results are presented in the tables while others are presented in narrative. The majority of participants stated that health experts recommend people should be eating more vegetables and less sugar, salty and fatty foods. It was also stated that health experts recommend cutting down on saturated fats as well (see Table 10).

\section{Knowledge: choices of food groups among primary caregivers}

The following tables focus on the choices that primary caregivers make based on their own nutritional knowledge.

A total of 97 (95.2\%) of participants selected ice - cream as being high in added sugar (see Table 11). Sixty-six (63.7\%) participants selected low fat spread to be low in fat. A total of $63(60 \%)$ selected nuts as being high in fat with $49(46.7 \%)$ selecting bread as also being high in fat. The majority of the participants 94 (89.5\%) selected luncheon meat (processed meat, salami) as being high in fat. One hundred and three (99\%) of participants selected pasta to be in the starchy food group. One hundred (95.2\%) of participants selected frozen vegetables as being high in salt with $76(72.4 \%)$ having selected cheese being low in salt. A total of $62 \%$ of participants selected cheese as being high in protein, with 52 (49.5\%) selecting cornflakes as being low in fiber. Questions pertaining to food high and low in fat had $63(60.3 \%)$ of participants correctly selecting olive oil as being low in 
Table 10. Diet recommendations.

\begin{tabular}{|c|c|}
\hline \multicolumn{2}{|l|}{ Diet Recommendations } \\
\hline Diet Recommendations & $\begin{array}{l}\text { Total sample } \\
\mathrm{N}=102(\%)\end{array}$ \\
\hline $\begin{array}{l}\text { Do you think health experts recommend that people should be eating } \\
\text { more, the same amount or less of these foods - Vegetables }\end{array}$ & $\begin{array}{l}\text { More }=98(96.0 \%) \\
\text { Same }=3(2.9 \%) \\
\text { Less }=0 \\
\text { Not Sure }=1(.9 \%)\end{array}$ \\
\hline $\begin{array}{l}\text { Do you think health experts recommend that people should be eating } \\
\text { more, the same amount or less of these foods - Fruit }\end{array}$ & $\begin{array}{l}\text { More }=81(79.4 \%) \\
\text { Same }=19(18.6 \%) \\
\text { Less }=1(.9 \%) \\
\text { Not Sure }=1(.9 \%)\end{array}$ \\
\hline $\begin{array}{l}\text { Do you think health experts recommend that people should be eating, } \\
\text { the same amount or less of these foods - Fatty Foods }\end{array}$ & $\begin{array}{l}\text { Same }=7(6.6 \%) \\
\text { Less }=95(93.4 \%)\end{array}$ \\
\hline $\begin{array}{l}\text { Do you think health experts recommend that people should be eating } \\
\text { more, the same or less of these foods - High fibre }\end{array}$ & $\begin{array}{l}\text { More }=73(71.5 \%) \\
\text { Same }=24(24 \%) \\
\text { Not sure }=4(4 \%)\end{array}$ \\
\hline $\begin{array}{l}\text { Which fat do experts say is the most important for people to cut down } \\
\text { on: Mono-unsaturated, poly-unsaturated, saturated or not sure. }\end{array}$ & $\begin{array}{l}\text { Mono - unsaturated }=6(5.8 \%) \\
\text { Poly - unsaturated }=18(17.6 \%) \\
\text { Saturated }=49(48.0 \%) \\
\text { Not Sure }=29(28.4 \%)\end{array}$ \\
\hline $\begin{array}{l}\text { Do you think health experts recommend that people should be eating } \\
\text { more, the same amount or less of these foods - Salty Foods }\end{array}$ & $\begin{array}{l}\text { Same }=4(3.9 \%) \\
\text { Less }=98(96 \%)\end{array}$ \\
\hline $\begin{array}{l}\text { Do you think health experts recommend that people should be eating } \\
\text { more, the same amount or less of these foods - Sugar }\end{array}$ & $\begin{array}{l}\text { Same }=2(1.9 \%) \\
\text { Less }=100(98.1 \%)\end{array}$ \\
\hline
\end{tabular}

Table 11. Choices of food groups.

\begin{tabular}{ll}
\hline \multicolumn{2}{c}{ Choices of Food Groups } \\
\hline & \multicolumn{1}{c}{ Total sample } \\
Food Groups & $\mathrm{N}=102(\%)$ \\
\hline Ice-cream is high in added sugar & High $=97(95.2 \%)$ \\
& Low $=2 \%(1.9)$ \\
& Not sure $=3(2.9 \%)$ \\
Low-fat spread is low in fat & High $=32(31.3 \%)$ \\
& Low $=66(63.7 \%)$ \\
& Not sure $=5(4.9 \%)$ \\
\hline
\end{tabular}

saturated fat and whole milk being high $53(50.5 \%)$ in saturated fat. The results suggest that in general parents were inclined to encourage balance and variety in the food intake of their children $(M=4.07, S D=0.71)$, model healthy eating behavior $(M=3.66, S D=0.86)$, monitor the food intake of children $(M=3.74, S D$ $=0.93)$, restrict unhealthy foods $(M=3.23, S D=0.89)$, as well as teaching about nutrition to encourage healthy food consumption $(M=3.00, S D=0.79)$. Additionally, parents seem to not use food to regulate their children's emotions $(M=1.74, S D=0.65)$ nor offer food as a reward $(M=2.26, S D=0.90)$.

Current diet regime of parents and caregivers varied greatly as indicated by Table 12, with most selecting a low-fat diet as their preferred choice. This could suggest that many of the parents and caregivers are either trying to improve their personal diet choices, and therefore make perceived better choices by sticking to 
Table 12. Diet regime of parents and caregivers.

\begin{tabular}{lc}
\hline \multicolumn{2}{c}{ Diet Regime of Parents and Caregivers } \\
\hline Parent/Caregiver Diet & Percentage \\
\hline Mediterranean diet & 6.7 \\
Low fat diet & 69.5 \\
High fat, low carb/Banting diet & 7.6 \\
High protein, low carb diet & 11.4 \\
Sugar free diet & 4.8 \\
Total & $\mathbf{1 0 0}$ \\
\hline
\end{tabular}

a low-fat diet. This is based on exposure to literature or advertising and the use of restrictive feeding behavior as a means to control their child's food intake to restrict weight $(M=1.94, S D=0.74)$.

\section{Discussion}

In this study, participants responded positively to the understanding of foods that should be minimally ingested, such as fats, sugars, and salt. Based on participants questionnaire responses they were also aware of the foods which needed to be increased in the diet, such as fiber, fruit, and vegetables.Given the complexity of the family meal structure, parenting style, feeding style, and feeding practices are defined within broad constructs to simplify research and to promote understanding. The general ways in which parents interact with their children (parenting style) and particularly during meals and snack times (feeding style) may influence parents' choice of feeding practices or the outcomes of these practices (Collins, Duncanson, and Burrows 2014; Larsen et al. 2015; Stang and Loth 2011).Actual knowledge of nutrition can be defined as habits involving regular eating patterns and vegetable intake (Brown and Roman 2015). The general public selects their foods from hundreds or even thousands of products, many of which are designed and marketed to maximize their appeal. The majority of the participants in the current study were however still able to select food that were balanced as well as limit consumption of unhealthy foods. It would seem that knowledge of nutrition or food choices plays a key role as part of a healthy lifestyle. (Swinburn et al. 2011). Parents are influential in shaping children's eating behaviors, including food preferences, food consumption, general diet quality and ultimately weight status (Boots et al. 2015). Based on parents' current dietary patterns of a low-fat diet it seems to be in alignment with the fact that they are practicing healthy food choices or trying to maintain their own weight. However, it must be stated that very little research has examined the relation between parent dieting and their food parenting (Robert, Goodman, and Musher-Eizenman 2018). Parental influence can be through modeling of food consumed as well as the availability and accessibility of food in the home (Boots et al. 2015). Parents can also influence children's eating behaviors by using deliberate feeding strategies, such as encouraging their children to eat 
more of specific foods, keeping track of what their child eats, and controlling the consumption of certain foods by restricting access to these foods (Boots et al. 2015). A small amount of research has examined the relation between some aspects of socioeconomic status (specifically parental education level) and food parenting (Robert, Goodman, and Musher-Eizenman 2018). Findings suggest that parents with higher levels of education make sugar-sweetened beverages less available in the home and their children consume fewer snacks and sugarsweetened beverages (Robert, Goodman, and Musher-Eizenman 2018). Similarly, parents with higher levels of education were found to monitor and restrict their children's food intake and were less likely to pressure their children to eat (Robert, Goodman, and Musher-Eizenman 2018). These findings are in agreement with previous literature (Robert, Goodman, and Musher-Eizenman 2018). The majority of parents in the current study were educated and had degree qualifications. The parents were found to be involved, supportive, as well as providing monitoring of their children and their choices of food in the current study, this being done through limiting and restricting unhealthy foods. Authoritative attempts to encourage eating (i.e., making high demands on children but in a responsive manner) may sometimes be associated with healthier eating styles and healthier body weights (van der Horst and Sleddens 2017). In order to select a healthy diet, an individual must be able to ignore the advertisers' blandishments and the immediate appeal to the palate, and draw on a complex, technical and scientific knowledge base concerning nutrients, foods, and health (Paramenter, Waller, and Wardle 2000). At a minimum, they need to know the prevailing nutritional recommendations, be able to apply those to the food products which they are considering consuming and combine recommendations to make the best food choices (Paramenter, Waller, and Wardle 2000). What and how parents feed their children shapes early eating habits and consequent risks for excess weight gain and obesity (Jansen et al. 2014). In this study, parents scored high in structure in parenting as well as having a strong correlation between autonomy supportive parenting and involvement. Jansen et al. (2014) states that healthy eating is promoted by parental responsibility for structuring the feeding environment - the what, when and where of food provision (i.e., 'demandingness' characterised in terms of 'limits' and 'structure' rather than 'control') - combined with supportive parental responses to children's cues of hunger and satiety, allowing the child to determine whether and how much to eat (i.e., responsiveness). Together these behaviors create a predictable, developmentally appropriate feeding environment, which allows children to attend to and recognize internal hunger and satiety cues and to maintain their capacity to self-regulate energy intake (Jansen et al. 2014). Child eating self-regulation develops across the lifespan from early childhood. The effect of this self-regulatory capacity would have a high impact on children's overall health and weight status. 


\section{Strengths, limitations of the study and future directions}

Although this study provides interesting findings, the results should be interpreted within limitations and should, therefore, be interpreted with caution. This study only focused on parents in parenting forums who were on social media; thus, the findings cannot be generalized to a larger sample of primary caregivers. In addition, most of those who participated in the study had higher education levels, which means that a sample of primary caregivers with lower education levels may provide different results. The data come with limitations inherent in using selfreported data (e.g., social desirability bias, self-selection). Conducting an online mode of data collection may not necessarily be the best option to conduct a study of this nature, as it is likely that if parents and primary caregivers were unsure of answers, they could Google it. The sample of the study was small, which may have been due to primary caregivers having children older than 18 years of age or younger than the age of 3 . There is also the awareness that feeding styles would change across the span of children's ages, but the focus was on parental perceptions more than individual child's age. A larger sample could provide different results, especially with regard to statistical comparisons between groups. Another further limitation lies in the use of the CFQ. This measures highly controlling feeding strategies such as restricting the type and amount of certain food, using food as a reward and monitoring the intake of certain foods. Thus, it neglects to examine a wider range of potential strategies that parents may use to control their child's food intake. Parents who are employed at full time may have less time to devote to teaching children about nutrition and involving them in meal preparation and may instead resort to practices such as simply restricting portions of fattening foods. There is a shortage of data on the effectiveness of obesity prevention efforts targeting parents as the main risk factors due to obesity always being shown to be linked to familial and environmental conditions. Therefore, this can be applied in practice by addressing parents directly through educational means that take into account their lifestyle and time constraints which affect their sharing of nutritional knowledge with their children. Future research may also explore how the child's weight affects parent feeding strategies there is not enough research to show that there is an increase in children's weight status. Further research is required to study the effect of parent's BMI on food parenting practices as parents may currently be dieting to control their own weight status.

\section{Funding}

This work was supported by the National Research Foundation (NRF) South Africa (110805).

\section{ORCID}

Melissa Brown (1) http://orcid.org/0000-0002-0375-4057 


\section{References}

Barber, B. K. 2002. Reintroducing parental psychological control. In Intrusive parenting: How psychological control affects children and adolescents, ed. B. K. Brian, pp. 15-22 . Washington: American Psychological Association.

Blissett, J. 2011. Relationships between parenting style, feeding style and feeding practices and fruit and vegetable consumption in early childhood. Appetite 57:826-31. doi:10.1016/j. appet.2011.05.318.

Boots, S., M. Tiggemann, N. Corsini, and J. Mattiske. 2015. Managing young children's snack food intake. The role of parenting style and feeding strategies. Appetite 92:94-101. doi:10.1016/j.appet.2015.05.012.

Brown, M., and N. Roman. 2014. Nutritional knowledge, feeding practices and body mass index of primary caregivers : a cross-sectional study. African Journal for Physical Health Education, Recreation and Dance.p. 312-324

Campbell, K., N. Andrianopoulos, K. Hesketh, K. Ball, D. Crawford, and L. Brennan, et al. 2010. Parental use of restrictive feeding practices and child bmi z-score. a 3-year prospective cohort study. Appetite 55:84-88. doi: 10.1016/j.appet.2010.04.006.

Cardel, M., A. L. Willig, A. Dulin-Keita, K. Casazza, T. M. Beasley, and J. R. Fernández. 2012. Parental feeding practices and socioeconomic status are associated with child adiposity in a multi-ethnic sample of children. Appetite 58 (1):347-53. doi:10.1016/j.appet.2011.11.005.

Carlo, G., M. V. Mestre, P. Samper, A. Tur, and B. E. Armenta (2010). The longitudinal relations among dimensions of parenting styles, sympathy, prosocial moral reasoning, and prosocial behaviors.int. J. Behav. Dev.35 116-124. doi:10.1177/0165025410375921

Carnell S, Wardle J. Associations between multiple measures of parental feeding and children's adiposity in United Kingdom pre-schoolers. Obesity. 2007; 15:137-144.

Davids, E. L., N. V. Roman, and L. Leach. 2015. The effect of family structure on decision-making, parenting styles and healthy lifestyle behaviour of adolescents in rural South Africa. African Journal of Physical, Health Education, Recreation and Dance 21 (3:2):953-67.

De Onis, M., M. Blössner, and E. Borghi. 2010. Global prevalence and trends of overweight and obesity among preschool children. The American Journal of Clinical Nutrition 92 (5):1257-1264. doi:10.3945/ajcn.2010.29786.

Dehghan, M., N. Danesh, and A. Merchant. 2005. Childhood obesity, prevalence and prevention. Nutrition Journal 4:24-28. doi: 10.1186/1475-2891-4-24.

Fisher, JO, and LL. Birch. 1999. Restricting access to palatable foods affects children's behavioral response, food selection, and intake. The American Journal Of Clinical Nutrition 69:1264-1272. doi:10.1093/ajcn/69.6.1264.

Galloway, A. T., L. Fiorito, Y. Lee, and L. L. Birch. 2005. Parental pressure, dietary patterns, and weight status among girls who are "Picky eaters". Journal of the American Dietetic Association 105:541-48. doi:10.1016/j.jada.2005.01.029.

Galloway, A. T., L. M. Fiorito, L. A. Francis, and L. L. Birch. 2006. 'Finish your soup': Counterproductive effects of pressuring children to eat on intake and affect. Appetite 46:318-23. doi:10.1016/j.appet.2006.01.019.

Gottman, J. M., and J. DeClaire. 1997. The heart of parenting: raising an emotionally intelligent child. New York, NY: Simon \& Schuster.

Hughes, S. O., T. G. Power, J. O. Fisher, S. Mueller, and T. A. Nicklas. 2005. Revisiting a neglected construct: Parenting styles in a child-feeding context. Appetite 44:83-92. doi:10.1016/j.appet.2004.08.007.

Jansen, E., K. M. Mallan, J. M. Nicholson, and L. A. Daniels. 2014. The feeding practices and structure questionnaire: Construction and initial validation in a sample of Australian 
first-time mothers and their 2-year olds. The International Journal of Behavioral Nutrition and Physical Activity 11:72. doi:10.1186/1479-5868-11-72.

Johnson, R., G. Welk, P. F. Saint-Maurice, and M. Ihmels. 2012. Parenting styles and home obesogenic environments. International Journal Of Environmental Research And Public Health 9:1411-1426. doi: 10.3390/ijerph9041411.

Kiff, C. J., L. J. Lengua, and M. Zalewski. 2011. Nature and nurturing: Parenting in the context of child temperament. Clinical Child and Family Psychology Review 14 (3):251-301. doi:10.1007/s10567-011-0093-4.

Larsen, J. K., R. C. Hermans, E. F. Sleddens, R. C. Engels, J. O. Fisher, and S. S. Kremers. 2015. How parental dietary behavior and food parenting practices affect children's dietary behavior. Interacting sources of influence?. Appetite 89:246-57. doi:10.1016/j.appet.2015.01.017.

Lipowska, M, M Lipowski, P Jurek, AM Jankowska, and Pawlicka P. Pawlicka. 2018. Gender and body-fat status as predictors of parental feeding styles and children's nutritional knowledge, eating habits and behaviours. International Journal Of Environmental Research and Public Health 15 (5):852. doi:10.3390/ijerph15050852.

Louw, D., and A. Louw. 2007. Child and adolescent development. South Africa: ABC Printers.

Moran, K. M., N. A. Turiano, and A. L. Gentzler. 2018. Parental warmth during childhood predicts coping and well-being in adulthood. Journal of Family Psychology 32 (5):610-21. doi:10.1037/fam0000401.

Musher-Eizenman, D., and S. Holub. 2007. Comprehensive feeding practices questionnaire: validation of a new measure of parental feeding practices. Journal Of Pediatric Psychology 32 (8): 960-972. doi: doi.10.1093/jpepsy/jsm037.

Paramenter, K., J. Waller, and J. Wardel. 2000. Demographic variation in nutrition knowledge in england. Health Education Journal 15 (2):163-174.

Paramenter, K., J. Waller, and J. Wardle. 2000. Demographic variation in nutrition knowledge in England. Health Education Research 15:163-74. doi:10.1093/her/15.2.163.

Paterson, A. D., K. A. Babb, A. Camodeca, J. Goodwin, J. Hakim-Larson, S. Voelker, and M. Gragg. 2012. emotion-related parenting styles (erps): a short form for measuring parental meta-emotion philosophy. Early Education \& Development 23 (4):583-602. doi: 10.1080/ 10409289.2011.569316.

Paulis, W. 2016. Childhood obesity in primary care: Not yet general practice. Rotterdam: Erasmus University Rotterdam.

Robert, L., L. Goodman, and D. Musher-Eizenman. 2018. Parental correlates of food parenting practices: Socioeconomic status, weight, and dieting status. Ecology of Food and Nutrition 57 (4):330-45. doi:10.1080/03670244.2018.1492381.

Roman, N. 2015. Parenting: Behaviors, cultural influences and impact on childhood health and well-being. Nova Science Publishers, Inc.

Savage, J. S., J. O. Fisher, and L. L. Birch. 2007. Parental influence on eating behavior: Conception to adolescence. The Journal of Law, Medicine \& Ethics 35:22-34. doi:10.1111/j.1748-720X.2007.00111.x.

Scaglioni, A., C. Arrizza, F. Vecchi, and S. Tedeschi. 2011. Determinants of children's eating behaviour. American Journal of Clinical Nutrition 94 (6):2006S-2011S. doi:10.3945/ ajcn.110.001685.

Schaefer, E. S. 1965. children's reports of parental behavior: an inventory. Child Development 36:413-424. doi:10.2307/1126465.

Shloim, N., L. R. Edelson, N. Martin, and M. M. Hetherington. 2015. Parenting styles, feeding styles, feeding practices, and weight status in 4-12 year-old children: A systematic review of the literature. Frontiers in Psychology 6:1849. doi:10.3389/fpsyg.2015.01849. 
Skinner, E. A., J. G. Wellborn, and C. Regan. 1986. The parents as social context questionnaire (PASCQ): Parent and child-reports of parent involvement, structure, and autonomy support. (Tech Rep.). Rochester, NY: University of Rochester.

Spruijt-Metz, D., C. Li, E. Cohen, L. Birch, and M. Goran. 2006. Longitudinal influence of mother's child-feeding practices on adiposity in children. The Journal of Pediatrics 148:314-20. [PubMed]. doi:10.1016/j.jpeds.2005.10.035.

Stang, J., and K. A. Loth. 2011. Parenting style and child feeding practices: Potential mitigating factors in the etiology of childhood obesity. Journal of the American Dietetic Association 111:1301-05. doi:10.1016/j.jada.2011.06.010.

Suchman, NE, B Rounsaville, C DeCoste, and S. Luthar. 2007. Parental control, parental warmth, and psychosocial adjustment in a sample of substance-abusing mothers and their school-aged and adolescent children. Journal Of Substance Abuse Treatment 32:1-10. doi: 10.1016/j.jsat.2006.07.002.

Swinburn, B. A., G. Sacks, K. D. Hall, K. McPherson, D. T. Finegood, M. L. Moodie, and S. L. Gortmaker. 2011. The global obesity pandemic: Shaped by global drivers and local environments. The Lancet 378:804-14. doi:10.1016/S0140-6736(11)60813-1.

Toriola, A. L., V. Moselakgomo, B. Shaw, and C. Ter Goon. 2012. Overweight, obesity and underweight in rural black South African children. South African Journal of Clinical Nutrition 25:57-61. doi:10.1080/16070658.2012.11734406.

van der Horst, K., and E. F. C. Sleddens. 2017. Parenting styles, feeding styles and foodrelated parenting practices in relation to toddlers' eating styles: A cluster-analytic approach. PloS One 12 (5):e0178149. doi:10.1371/journal.pone.0178149.

Ventura, A. K., and L. L. Birch. 2008. Does parenting affect children's eating and weight status?. The International Journal of Behavioral Nutrition and Physical Activity 5:15. doi:10.1186/1479-5868-5-15.

Wang, L., V. M. van de Gaar, W. Jansen, C. L. Mieloo, A. van Grieken, and H. Raat. 2017. Feeding styles, parenting styles and snacking behaviour in children attending primary schools in multiethnic neighbourhoods: A cross-sectional study. BMJ Open 7 (7): e015495. doi:10.1136/bmjopen-2016-015495.

Webber, L., F. Kilpi, T. Marsh, K. Rtveladze, M. Brown, and K. McPherson. 2012. High rates of obesity and non-communicable diseases predicted across Latin America. PloS One 7 (8): e39589. doi:10.1371/journal.pone.0039589.

Webber, L., L. Cooke, C. Hill, and J. Wardle. 2010. Child adiposity and maternal feeding practices: A longitudinal analysis. The American Journal of Clinical Nutrition 92:1423-28. doi:10.3945/ajen.2010.30112.

World Health Organization. 2008. Controlling the global obesity epidemic. Last accessed on 2018 Dec 18.www.who.int/nutrition/topics/obesity/en/. 